\title{
Innovation and Guarantee Mechanism of Poverty Alleviation Model in Rural Tourism
}

\author{
Meng Li \\ Xi'an University of Finance and Economics, Xi'an City, Shaanxi Province, 710100, China
}

Keywords: Rural tourism; Poverty alleviation; Innovation; Protection mechanism

\begin{abstract}
In recent years, the party and the state attach great importance to poverty alleviation and development in rural areas, and try to use rural resources to develop rural economy, and promote rural poverty alleviation through economic development. China's poor rural tourism resources are abundant and human power is abundant. Many poor rural areas have the conditions for developing rural tourism, and tourism poverty alleviation is an effective scientific path. Based on the author's learning and practical experience, this paper first analyzed the connotation of rural tourism precise poverty alleviation, and then discussed how to innovate the rural tourism poverty alleviation model, and finally put forward the rural tourism poverty alleviation mode protection mechanism, so that to provide some enlightenment for rural tourism and play a better role in poverty alleviation.
\end{abstract}

\section{Introduction}

With the decrease of rural poverty rate in our country, the idea of setting poverty alleviation target in poor areas in the past must be changed. The goal of poverty alleviation should be aimed at the poor areas and aimed at the poor population, so as to improve the precision of poverty alleviation. Tourism for the first time in 2011 as one of the ways of helping the poor is written into the "Outline of Chinese Rural Poverty Alleviation and Development(2011-2020)". The precision of poverty alleviation in rural tourism is not high in our country, and it has not been able to pinpoint the object of poverty alleviation in rural tourism and take targeted measures to help and manage it, which has led to the deviation of the goal of poverty alleviation in rural tourism. Under the background of poverty alleviation, the problem of how to innovate for the poverty alleviation model of rural tourism has become an urgent problem for the industry and the academic community.

\section{The Connotation of Precise Poverty Alleviation in Rural Tourism}

For the first time, the concept of "precise poverty alleviation in rural tourism" has been put forward at the national level. The seventh item in "a few opinions on promoting the reform of the tourism industry" is "strengthening rural tourism, and precisely helping the poor". The concept of precise poverty alleviation provides a strong guidance for rural tourism, but the precise poverty alleviation in rural tourism is not a simple solution to poverty alleviation. Under the framework of the concept of precise poverty alleviation and combined with the characteristics of rural tourism poverty alleviation, the concept of precise poverty alleviation is applied to the rural tourism poverty alleviation areas. The poor people in our country are mainly distributed in the vast rural areas, and there is a great coincidence between rich tourism resources and poor rural areas, which makes the establishment of an organic relationship between the development of tourism and poverty alleviation. Therefore, the precise poverty alleviation in rural tourism must combine the tourism poverty alleviation with the rural tourism industry, and the great function possessed by the rural tourism industry can produce a thrust on the economic development of the poor rural areas. As a matter of fact, rural tourism is a typical form of industrial poverty alleviation, which is a kind of poverty alleviation through the driving role of tourism economy to the rural regional economy. The accurate poverty alleviation in rural tourism is to strengthen the "hematopoietic function" type of poverty alleviation. It is different from the previous implementation of material donations, poverty alleviation, civil relief, poverty alleviation, financial poverty alleviation and credit poverty 
alleviation and other blood transfusion relief. Moreover, rural tourism emphasizes poverty alleviation and the benefits of poor people's participation in rural tourism development, and reflects the promotion of the self capacity of rural poor population. It shakes off the poverty both from the economy and spirit. Therefore, precise poverty alleviation in rural tourism is a new pattern of poverty alleviation through using the scientific and effective procedures and methods to identify and make accurate identification, accurate help and accurate management to the target of rural tourism poverty alleviation. As a result, it will achieve the goal of "helping the poor" in rural tourism poverty alleviation.

\section{The Innovation of Poverty Alleviation Model in Rural Tourism}

Government guiding and policy leading. First of all, the government should make scientific planning, formulate plans and related policies for the development of poverty alleviation in rural tourism, and make clear the orientation, scope and mode of poverty alleviation in rural tourism. Secondly, the government should encourage and guide rural poor farmers to integrate into rural tourism development and management through positive support policies and financial support. Once again, the government should strengthen and improve the infrastructure construction of rural tourism, focusing on strengthening environmental improvement, road construction, afforestation, tourism infrastructure and public service system construction.

Suit measures to local conditions and diversified development. The development of poverty alleviation in rural tourism needs to be adjusted according to local conditions, and diversified development should be differentiated according to different resource characteristics in poor areas. We should make full use of the countryside rural scenery, pastoral landscape, characteristics of residential buildings. Moreover, we have to help folk customs, agricultural festival and farming culture connotation, so that to show characteristics and gather human spirit. On the one hand, people enter a new era of leisure, so leisure vacation has become a rigid demand and people's new way of life. On the other hand, with the arrival of the aging population, health care for the elderly has attracted much attention, and health has become a lifestyle and social hot spots. Therefore, leisure vacation and health care for the elderly will be the most potential growth point in the future rural tourism market. In this regard, the rural areas have unique resource advantages and development advantages.

Make integration of resources and three-dimensional poverty alleviation. Without integration, resources can not be effectively gathered, nor can they maximize the benefits. Tourism poverty alleviation should use multi pronged approach and three-dimensional poverty alleviation. We should cover poverty alleviation projects, funding, policies, mechanisms and measures. Rural tourism should integrate rural tourism resources and production factors, make the six elements of tourism rational and advanced and create a bright spot of rural tourism industry, so as to form scale effect. Secondly, we should integrate and utilize the rich rural culture, unique folk customs, distinctive rural features, rural products and wonderful country stories. We also need to mould the image, play the brand, strengthen the market competition advantage, enhance the market competition ability, and realize the sustainable development of the rural tourism to help the poor. Once again, we should integrate social resources, use policy advantages, and strive for funds, technology, talent support and improve infrastructure and hardware and software environment. Consequently, we can raise the ideological and political awareness and management ability of the poor population, and improve the efficiency of poverty alleviation through rural tourism.

Accurate identification and precision poverty alleviation. Precise poverty is a new strategy for poverty alleviation in China and it is different from the previous extensive flooding and poverty alleviation. It emphasizes the use of scientific and effective methods and procedures for accurate identification, accurate help and accurate management of poor objects in different environments and conditions. Therefore, poverty alleviation in rural tourism should firstly identify the target population and poverty alleviation projects scientifically, and identify the targets and contents. The poverty alleviation in rural tourism should ensure that the goal of poverty alleviation is not deviated, so as to strengthen the pertinence of poverty alleviation in rural tourism, and improve the efficiency 
of the allocation of anti-poverty resources in rural tourism. Second, we should refine the two aspects of people and money to ensure that the measures are implemented to households and people. We should allow poor farmers to participate in and share the benefits of rural tourism, so that to help farmers improve their ability to manage tourism. Third, we must develop in an orderly way, manage scientifically, guide the tour operators in strict accordance with the standard and standard management, and maintain the order of the tourist market and take the road of sustainable development.

Marketing driven and brand promotion. The development of poverty alleviation in rural tourism needs the key elements of rural tourism attraction, such as colorful rural features, unique folk customs, wonderful stories and legends, and special materials and goods. They use network terminals, mobile terminals, large screen and other marketing channels to publicize. Specifically, we can integrate resources, build official website of rural tourism, mobile portal or develop rural tourism APP, enrich publicity information and enhance the online service function of rural tourism. We can also work with sina, Tencent, NetEase and other portals to open the official micro-blog for rural tourism, and open the rural tourism SNS community through using WeChat and other modern media and tools. We can also shoot micro video and micro film through the full displaying of multimedia resources and rural village style. We can also work with virtual tourism enterprises to demonstrate the rural tourism resources and products, and enhance the visitors' perception through virtual 3D software.

\section{The Guarantee Mechanism of Rural Tourism Poverty Alleviation Model}

Strengthen government leading. We will further strengthen government leadership and ensure the fundamental protection of the government in terms of organization, funding and policy; we has strengthened the government's efforts in capital investment and policy support (finance, taxation, finance, industry, ecological compensation, talents); we should strengthen the government's efforts in scientific planning, planning management, fund management, monitoring and evaluation, and social assistance; we should play the important role of the government in environmental construction, marketing promotion, regional coordination and environmental protection and so on.

Increase policy support. As for the financial support, we should increase the transfer payments, investment in poverty alleviation and development, the implementation of preferential tax policies, poverty alleviation and development innovation tax policy. In terms of financial services, we should set up poverty alleviation and development zones, branches of commercial banks, develop new financial institutions, set up various investment funds and develop venture capital; we will set up a special fund for the construction of the credit guarantee system. In terms of industrial support, we should give preferential policies to major projects, key projects and tourism related industries. We should give priority to the protection of major tourist attractions, infrastructure services, and the development of advantageous resources. At the same time, we should explore the establishment of paid use of environmental capacity, water rights trading, emission trading mechanism, and also establish and improve the mechanism of public welfare forest management.

Innovative regional cooperation mechanism. Actively construct the barrier free tourism cooperation mechanism, including cross regional organization coordination mechanism, benefit distribution mechanism, ecological compensation mechanism, evaluation incentive mechanism and behavior restraint mechanism. We should build a new pattern of regional tourism cooperation, such as the cross regional Executive Council, the coordination of government departments, the joint meeting of the administrative departments of tourism and other regional cooperation mechanisms, so that to promote coordinated development. We should give development ideas, define the principles and frameworks for the adjustment of major interests, and coordinate and resolve relevant policies and issues in cooperation. Further more, we should carry out the planning link up, the infrastructure docking, the industrial layout integration, the division of labor and cooperation mechanism. We should properly handle the distribution of interests in the upper and lower reaches of the industrial chain, the opening of regional markets and the flow of factors. 
Clear the responsibilities of the tourism sector. We should strengthen planning guidance, implement the plan of tourist talents and increase marketing efforts. In particular, it is necessary to formulate and implement urgently needed personnel support programs to provide intellectual support for poverty alleviation and development. We should set up a training mode of tourist talents, and form a diversified pattern of personnel training, which is guided by the government, schools and enterprises, industry associations and other social forces. We should further improve the personnel incentive mechanism and policy system, and improve the management mechanism of tourism talents; we should promote the rational distribution and flow of regional and departmental tourism talents and promote the leapfrog development of the tourism industry.

\section{Summary}

If we want to realize the rural poverty alleviation, we must give full play to the comprehensive driving role of rural tourism, promote the integration and development of the first, secondary and tertiary industries at rural areas, and improve the operational efficiency of all aspects of rural society. Therefore, the government should take the lead in poverty alleviation in rural tourism, strengthen strategic guidance and innovate the mechanism and mechanism. Moreover, rural tourism should give full play to the main role of the enterprise, realize poverty alleviation through industrial development, and make rural tourism become the main channel and backbone of the new round of poverty alleviation and development in rural areas.

\section{Acknowledgement}

Youth Fund Project of 2017 Ministry of Education Humanities and Social Sciences Research: Evaluation and optimization of government supply efficiency in agricultural vocational education in Western China - Taking Shaanxi Province as an example

\section{References}

[1] Yang Liu. The Performance and Empirical Study of Poverty Alleviation in Rural Tourism[J]. China Agricultural Resources and Division, 2017, (05): 217-221.

[2] Wu Jingnan. Study on the Path of Rural Tourism Precision Poverty Alleviation[J]. Rural Economy, 2017, (03): 99-103.

[3] Lu Chunyang, Wen Feng, Wang Jinfeng, Si Jin, Xie Lidan, Qin Yan. Rural Tourism Lidan, and Poverty Aalleviation Precise Linkage Research[J]. Rural Economy and Science and Technology, 2017, (03): 92-94.

[4] Fu Zhanjuan. Research and Application, Research on Rural Tourism Poverty Alleviation Agriculture[J]. 2017, (01): 60-65.

[5] Zhou Jianhua, Shen Guoqi. Study on the Evaluation System and Influencing Factors of Poverty Alleviation in Rural Tourism[J]. Journal of Huzhou Teachers College, 2016, (11): 1-9.

[6] Mao Feng. Innovation and Strategy Deepening of Poverty Alleviation Model in Rural Tourism[J]. China Agricultural Resources and Regionalization, 2016, (10): 212-217.

[7] Chen Qiuhua, Ji Jinxiong. Study on the Path of Poverty Alleviation in Rural Tourism[J]. Fujian Forum (Humanities aand Social Science), 2016, (05): 196-200. 